\title{
Updates on the Facilities, Procedures, and Performance of the Accredited Endoscopy Unit
}

\author{
Tae Hee Lee ${ }^{1}$, Jin Young Yoon ${ }^{2}$, Chang Nyol Paik ${ }^{3}$, Hyuk Soon Choi ${ }^{4}$, Jae-Young Jang ${ }^{1}$ and The Quality Management Committee of \\ The Korean Society of Gastrointestinal Endoscopy \\ ${ }^{1}$ Institute for Digestive Research, Soonchunhyang University Seoul Hospital, Seoul, ${ }^{2}$ Department of Internal Medicine, Kyung Hee University \\ College of Medicine, Seoul, ${ }^{3}$ Department of Internal Medicine, The Catholic University of Korea, St. Vincent's Hospital, Suwon, ${ }^{4}$ Department \\ of Internal Medicine, Korea University College of Medicine, Seoul, Korea
}

Endoscopic quality indicators can be classified into three categories, namely facilities and equipment, endoscopic procedures, and outcome measures. In 2019, the Korean Society of Gastrointestinal Endoscopy updated the accreditation of qualified endoscopy unit assessment items for these quality indicators to establish competence and define areas of continuous quality improvement.

Here, we presented the updated program guidelines on the facilities, procedures, and performance of the accredited endoscopy unit. Many of these items have not yet been validated. However, the updated program will help in establishing competence and defining areas of continuous quality improvement in Korean endoscopic practice. Clin Endosc 2019;52:431-442

Key Words: Facility; Equipment; Process; Performance indicator

\section{INTRODUCTION}

The accreditation of qualified endoscopy unit (AQEU) assessment program was initiated in 2012 by the Korean Society of Gastrointestinal Endoscopy (KSGE) to enhance high-quality gastrointestinal (GI) endoscopy services. Based on the experience gained from the previous program, KSGE has updated this program in 2019. Endoscopic units aim at providing high-quality diagnostic and therapeutic endoscopy services. ${ }^{1}$ These units must be characterized by a comfortable and safe environment for patients and a productive and efficient environment for the staff. Quality assurance is a main concern in cases of endoscope malfunctions and inadequate repair. ${ }^{2}$ Accurate and adequate endoscopic processes improve the

Received: August 21, 2019 Revised: August 30, 2019

Accepted: September 5, 2019

Correspondence: Tae Hee Lee

Institute for Digestive Research, Digestive Disease Center, Soonchunhyang University Seoul Hospital, 59 Daesagwan-ro, Yongsan-gu, Seoul 04401, Korea Tel: +82-2-710-3084, Fax: +82-2-709-9696, E-mail: iman0825@schmc.ac.kr ORCID: https://orcid.org/0000-0003-3049-8252

(c) This is an Open Access article distributed under the terms of the Creative Commons Attribution Non-Commercial License (http://creativecommons.org/ licenses/by-nc/3.0) which permits unrestricted non-commercial use, distribution, and reproduction in any medium, provided the original work is properly cited. quality and safety of endoscopic practices. ${ }^{3}$ The measurement of endoscopic outcomes, such as safety and efficiency profiles, is mandatory to monitor and improve poor performance. ${ }^{3}$ These facility/equipment, procedures, and outcome measures serve as endoscopic quality indicators. In 2019, KSGE updated the AQEU assessment items for these quality indicators to establish competence and help in defining areas of continuous quality improvement. The AQEU assessment items for the facility and equipment are divided into the following categories (Table 1): endoscopes/accessories, facilities/spaces, and emergency aid equipment/patient monitoring systems. The assessment items comprise of a total of 23 items, including 16 mandatory items that require $100 \%$ compliance and 7 recommended items. The quality improvement items for the process are designed to assess processes before, during, and after the GI endoscopic procedures, including processes of explaining the procedure to the patients and obtaining patient consent for endoscopic examination, endoscopic examination itself, tissue biopsy, and interpretation of test results. There are a total of 20 items for process assessment, including 19 mandatory items and 1 recommended item (Table 2). The assessment of performance indicators comprises 14 items, including 10 mandatory and 4 recommended items (Table 3). Here, we 
Table 1. The Accreditation of Qualified Endoscopy Unit Assessment Items for Facility and Equipment

\begin{tabular}{|c|c|}
\hline Category & AQEU assessment items \\
\hline & Mandatory items (16 items) \\
\hline $\begin{array}{l}\text { Endoscopes/ } \\
\text { accessories } \\
\text { (3 items) }\end{array}$ & $\begin{array}{l}\text { 1. Endoscope must be checked and repaired regularly to determine damage and quality. } \\
\text { 2. Endoscopic therapeutic accessories that can be used for the treatment of any complications arising during an } \\
\text { endoscopic procedure must be readily available. } \\
\text { 3. Records of accessories related to endoscopic procedures must be kept. }\end{array}$ \\
\hline $\begin{array}{l}\text { Facilities/spaces } \\
\text { (7 items) }\end{array}$ & $\begin{array}{l}\text { 1. Separate changing rooms and lockers for male and female patients are required inside the endoscopy unit. } \\
\text { 2. For endoscopic examinations, bathroom facilities are required inside the endoscopy unit. } \\
\text { 3. A waiting area for patients is required. } \\
\text { 4. A patient consultation room or area is required inside the endoscopy unit. } \\
\text { 5. An endoscopic examination room, separate from the outpatient examination room, is required. } \\
\text { 6. For endoscopy under sedation, an area for patient recovery, independent of the examination room, is required. } \\
\text { 7. Curtains or partitions separating beds in the endoscopy recovery room are required. }\end{array}$ \\
\hline \multirow[t]{2}{*}{$\begin{array}{l}\text { Emergency aid } \\
\text { equipment/patient } \\
\text { monitoring system } \\
\text { (6 items) }\end{array}$} & $\begin{array}{l}\text { 1. The recovery room must be equipped with a pulse oximeter and oxygen, and a blood pressure monitor for } \\
\text { monitoring recovery from sedation. } \\
\text { 2. An emergency mobile cart with emergency medical supplies for cardiopulmonary resuscitation must be avail- } \\
\text { able and regularly maintained. } \\
\text { 3. Each bed in the examination room must be equipped with a patient monitoring system for checking blood } \\
\text { pressure, heart rate, and oxygen saturation. } \\
\text { 4. Each bed in the examination room must be equipped with oxygen-supply equipment. } \\
\text { 5. An electrocardiogram monitoring device must be available. } \\
\text { 6. A portable oxygen tank that could be used any time must be available. }\end{array}$ \\
\hline & Recommended items (7 items) \\
\hline $\begin{array}{l}\text { Facility and space } \\
\text { (7 items) }\end{array}$ & $\begin{array}{l}\text { 1. Endoscopy units that perform therapeutic endoscopic procedures are recommended to have } \mathrm{CO}_{2} \text { insufflator } \\
\text { systems and accessories. } \\
\text { 2. Installation of an appropriate ventilation system is recommended for all endoscopic examination rooms. } \\
\text { 3. The door in each endoscopic examination room should be wide enough to allow beds to pass freely through } \\
\text { the door, while the size of the room should accommodate the bed, preparation cart, and emergency cart. } \\
\text { 4. Endoscopy units are recommended to have a separate preparation room for preparation, formulation, and } \\
\text { storage of injections. } \\
\text { 5. Endoscopy units are recommended to have a general recovery area to allow for patient recover and stabiliza- } \\
\text { tion before discharge. } \\
\text { 6. There should be a separate area inside the endoscopy units for providing education to employees and patients. } \\
\text { 7. Endoscopy units are recommended to include a waiting/resting area for the medical staff. }\end{array}$ \\
\hline
\end{tabular}

AQEU, accreditation of qualified endoscopy unit.

${ }^{a}$ Although these are mandatory items, full compliance may be difficult with short-term preparation. Accordingly, if there are specific plans for future changes, the assessment may be deferred by 3 years until the next accreditation assessment.

present the updated program guidelines with respect to the facilities, procedures, and performance of the accredited endoscopy unit.

\section{RATIONALE FOR AQEU ASSESSMENT ITEMS FOR FACILITY, SPACE, AND EQUIPMENT}

\section{Mandatory items 16 items}

\section{Endoscopes/accessories: 3 items}

\section{Endoscopes must be examined and repaired regu- larly to assess damage and quality.}

Rationale: Regular care of the endoscopes and endoscope main body is mandatory for accurate endoscopic diagnosis. Regular care of the endoscopes and endoscope main body is required to extend the lifespan of the endoscopic equipment and to ensure accurate and safe endoscopic examinations while maintaining the resolution of endoscopy.

\section{Endoscopic therapeutic accessories that can be used for the treatment of any complications arising during an endoscopic procedure must be readily available.}

Rationale: Endoscopic accessories, which may be used to 
Table 2. The Accreditation of Qualified Endoscopy Unit Assessment Items for Process

\begin{tabular}{|c|c|}
\hline Category & AQEU assessment items \\
\hline & Mandatory items (19 items) \\
\hline $\begin{array}{l}\text { Explanation and } \\
\text { consent } \\
\text { (8 items) }\end{array}$ & $\begin{array}{l}\text { 1. Prior to endoscopic examination, the examiner or an assistant must verify the identity of the examinee by } \\
\text { name and date of birth. } \\
\text { 2. Information on the type of endoscopic examination, the reason for performing the procedure, and how the } \\
\text { procedure will be performed must be provided in advance. } \\
\text { 3. The consent form for upper GI endoscopy must use a recommended format or contain all mandatory infor- } \\
\text { mation. The complete consent should be obtained prior to the procedure. } \\
\text { 4. The consent form for colonoscopy must use a recommended format or contain all mandatory information. } \\
\text { The complete consent should be obtained prior to the procedure. } \\
\text { 5. The consent form provided prior to endoscopic examination must be signed by the medical staff and the ex- } \\
\text { aminee (or their legal representative). } \\
\text { 6. For sedation for endoscopy, the recommended format must be used or all information needed for sedation } \\
\text { consent must be included. } \\
\text { 7. Prior to endoscopic examination, a pre-screening chart or evaluation report must be checked for fasting status; } \\
\text { general condition; disease history; medication history, including use of antithrombotic agents; teeth conditions } \\
\text { (only for upper GI endoscopy only); and bowel preparation status (for colonoscopy only). } \\
\text { 8. Prior to colonoscopy, information must be provided to the examinee about the importance of bowel prepa- } \\
\text { ration and diet and use of a bowel-cleansing agent for bowel preparation. An information brochure must be } \\
\text { distributed. }\end{array}$ \\
\hline $\begin{array}{l}\text { Examination } \\
\text { processes } \\
\text { (8 items) }\end{array}$ & $\begin{array}{l}\text { 1. Images acquired during the endoscopic examination must be saved as image files. } \\
\text { 2. Upper GI endoscopy images must include } 8 \text { images of standard imaging areas. When imaging the stomach, } \\
\text { the entire stomach must be imaged and the images must be saved. } \\
\text { 3. Presence of Helicobacter pylori must be checked when gastric or duodenal ulcer is found during an upper GI } \\
\text { endoscopic examination. } \\
\text { 4. During colonoscopy, cecal intubation must be performed and whether cecal intubation was performed or not } \\
\text { must be recorded in the report. Images must be saved. } \\
\text { 5. Colonoscopy imaging must include images of the maximum intubation site and at least } 8 \text { images of standard } \\
\text { imaging areas, in the observed order, where there are no local lesions. Additional clear images must be ac- } \\
\text { quired as proof that the examination was performed sufficiently with scoping of the entire colon. } \\
\text { 6. During colonoscopy, the total examination and withdrawal times must be measured, and the average with- } \\
\text { drawal time must be at least } 6 \text { minutes. } \\
\text { 7. Tissue biopsy must be performed on any abnormal findings detected during endoscopic examination. } \\
\text { 8. Appropriate response measures for adverse events that may occur during endoscopic examination must be } \\
\text { established and implemented accordingly. }\end{array}$ \\
\hline \multirow[t]{2}{*}{$\begin{array}{c}\text { Test results } \\
\text { (3 items) }\end{array}$} & $\begin{array}{l}\text { 1. Patients must be notified after the endoscopic examination about the tissue biopsy or } H \text {. pylori testing per- } \\
\text { formed during the procedure and how to obtain the results. } \\
\text { 2. Verbal or written information about precautions or possible complications must be provided to the examinee } \\
\text { prior to discharge. } \\
\text { 3. Records must be kept on management of specimens obtained during endoscopic examinations. }\end{array}$ \\
\hline & Recommended item (1 item) \\
\hline $\begin{array}{l}\text { Test results } \\
(1 \text { item })\end{array}$ & 1. There should be guidelines for making revisions and changes to the endoscopic examination reports. \\
\hline
\end{tabular}

AQEU, accreditation of qualified endoscopy unit; GI, gastrointestinal.

respond appropriately to complications that may occur during endoscopy, such as bleeding, must be available to ensure a timely response to emergency situations and should be used and managed properly to ensure patient safety.

\section{Records of accessories related to endoscopic pro- cedures must be kept.}

Rationale: With respect to documentation for accessories used in endoscopic procedures, the amount used, remaining inventory, storage conditions, and expiration or usage dates should be recorded and maintained. The purpose of such practice is to generate an adequate level of inventory based on calculation of amount use over a set period of time and quality assurance for effective use of medical supplies and accessories. 
Table 3. The Accreditation of Qualified Endoscopy Unit Assessment Items for Performance Indicators

\begin{tabular}{|c|c|}
\hline Category & AQEU assessment items \\
\hline & Mandatory items (10 items) \\
\hline $\begin{array}{l}\text { Quality indicators in } \\
\text { upper GI endoscopy } \\
\text { (1 item) }\end{array}$ & $\begin{array}{l}\text { 1. The endoscopy report must include information that could be used to verify the following items: } \\
\text { (1) Examination date, (2) name, (3) sex, (4) age, (5) registration number, (6) name of the endoscopist, (7) de- } \\
\text { tails about drugs used (spasmolytic, sedative, etc.), (8) biopsy status, (9) observational findings, (10) diagnosis, } \\
\text { and (11) Helicobacter pylori test status. }\end{array}$ \\
\hline $\begin{array}{l}\text { Quality indicators in } \\
\text { colonoscopy } \\
\text { ( } 3 \text { items) }\end{array}$ & $\begin{array}{l}\text { 1. The endoscopy report must include information that could be used to verify the following items: } \\
\text { (1) Examination date, (2) name, (3) sex, (4) age, (5) registration number, (6) name of the endoscopist, (7) de- } \\
\text { tails about drugs used (spasmolytic, sedative, etc.), (8) biopsy status, (9) observational findings, (10) diagnosis, } \\
\text { (11) cecal intubation status, (12) quality of bowel preparation, and (13) endoscopic procedure time and with- } \\
\text { drawal time. } \\
\text { 2. The endoscopy report must describe the results from digital rectal examination and observation of the outside } \\
\text { of the anus prior to the endoscopic procedure. } \\
\text { 3. Adequate bowel preparation rate among all monthly colonoscopic examinations must be maintained at } \geq 80 \% \text {. }\end{array}$ \\
\hline $\begin{array}{l}\text { Common quality } \\
\text { indicators } \\
\text { (4 items) }\end{array}$ & $\begin{array}{l}\text { 1. When lesions (ulcer or polyp etc.) are found during the examination, the endoscopy report must describe } \\
\text { (1) number, (2) location, (3) gross morphology, and (4) size of the lesion(s). } \\
\text { 2. When an endoscopic treatment was performed on lesion(s), the endoscopy report must contain information } \\
\text { verifying } \\
\text { (1) treatment method and (2) request for histologic evaluation when the lesion was removed. } \\
\text { 3. The indication(s) for the endoscopic examination must be clearly stated in the endoscopy report. } \\
\text { 4. After endoscopy, complications associated with the examination must be described in the endoscopy report. }\end{array}$ \\
\hline \multirow[t]{2}{*}{$\begin{array}{l}\text { Longitudinal data } \\
\text { ( } 2 \text { items) }\end{array}$} & $\begin{array}{l}\text { 1. Monthly statistics on the number of endoscopic procedures performed must be available. } \\
\text { 2. Monthly statistics on the number of patients who underwent blood transfusion, were hospitalized, or under- } \\
\text { went surgery for complications that occurred during the endoscopic procedure must be available. }\end{array}$ \\
\hline & Recommended items (4 items) \\
\hline $\begin{array}{l}\text { Common quality } \\
\text { indicators } \\
(1 \text { item })\end{array}$ & $\begin{array}{l}\text { 1. The endoscopy report should include any major disease history (hypertension, diabetes, heart disease, liver } \\
\text { disease, etc.) and medication history (antithrombotic agent and medication for hypertension, diabetes, or oth- } \\
\text { ers). }\end{array}$ \\
\hline $\begin{array}{l}\text { Longitudinal data } \\
\text { (3 items) }\end{array}$ & $\begin{array}{l}\text { 1. Calculation of monthly statistics on the detection rate of adenoma on colonoscopy is recommended. } \\
\text { 2. Calculation of monthly statistics on detection rates of cancer following upper GI endoscopy or colonoscopy is } \\
\text { recommended. } \\
\text { 3. Collection of statistical data on the assessment of sedation level during endoscopy and complications associat- } \\
\text { ed with sedation is recommended. }\end{array}$ \\
\hline
\end{tabular}

AQEU, accreditation of qualified endoscopy unit; GI, gastrointestinal.

\section{Facilities/spaces: 7 items}

\section{Separate changing rooms and lockers for male and female patients are required inside the endos- copy unit.}

Rationale: In particular, all patients undergoing colonoscopy must wear an examination gown. In such cases, separate changing rooms for male and female patients should be provided, where the patients could keep their clothes and personal belongings.

\section{For endoscopic examinations, bathroom facilities are required inside the endoscopy unit.}

Rationale: Bowel preparation is required for colonoscopy. ${ }^{4}$ Bathrooms must be available for bowel preparation, enema as rescue for inadequate bowel preparation, and post-procedural self-care.

\section{A waiting area for patients prior to their endo- scopic examination is required.}

Rationale: Prior to the endoscopic procedure, patients may feel tension, which may cause changes in their vital signs, such as blood pressure and heart rate. Accordingly, a comfortable waiting area is required for patients. Some endoscopic procedures may be longer, and thus, a bulletin board or monitor should be set up to provide updates on the progress of the endoscopic examination or procedure. It is recommended that educational materials and videos are available in the waiting area to minimize anxiety about the endoscopic examination and procedure. 
4. A patient consultation room or area is required inside the endoscopy unit.

Rationale: As patient education is essential for safe endoscopy, obtaining consent from patients using a form and explaining the procedure to the patients are becoming mandatory. Especially with the increase in the number of therapeutic endoscopic procedures, there is a higher number of cases wherein information must be provided to the patient and guardian before, during, and after the procedure. Therefore, it is absolutely necessary to maintain a patient consultation area inside the endoscopy unit.

\section{An endoscopic examination room separated from} the outpatient examination room is required.

Rationale: The saliva, blood, and feces of patients are collected in endoscopic examination rooms. In addition, various complications may occur inside this room due to different drugs used when endoscopy under sedation is performed. Therefore, it is necessary to have this area separated from other examination rooms, in order to prevent infection and to allow for provision of emergency care.

\section{For endoscopy under sedation, an area for patient} recovery, independent of the examination room, is required.

Rationale: Emergency situations may occur during endoscopy under sedation, and thus, sufficient space, equipment, and personnel are required to monitor and respond to such situations.

\section{Curtains or partitions separating the beds in the endoscopy recovery room are required.}

Rationale: Patients recover after an endoscopic procedure in the endoscopy recovery room. Due to the increase in the number of patients requiring endoscopy under sedation, the number of patients requiring an endoscopy recovery room is also increasing. In some cases, patients may pose a risk of infection to other patients; thus, recovery room beds must be separated by curtains or partitions. Moreover, some patients may present with incomplete recovery of cognitive functions after endoscopy under sedation; thus, it is absolutely necessary to provide partitions between beds for privacy.

\section{Emergency aid equipment/patient monitoring sys- tem: 6 items}

1. The recovery room must be equipped with a pulse oximeter, oxygen, and blood pressure manometer for monitoring recovery from sedation.

Rationale: Different patients show various rates of recovery from sedation after an endoscopic procedure, and accordingly, the recovery room must include equipment for continuous patient monitoring until patients recover completely from sedation. ${ }^{5}$

\section{An emergency mobile cart with emergency med-} ical supplies for cardiopulmonary resuscitation and emergency care must be available and regularly maintained.

Rationale: During an endoscopic procedure, severe adverse events (AEs), such as respiratory distress, hypotension, and shock may occur; thus, emergency medical supplies and equipment must be available for potential emergency responses. When performing endoscopy, emergency medication, such as epinephrine, and emergency resuscitation equipment, including a cardiopulmonary function monitor, intubation instruments, and artificial respiratory equipment, must be available. In addition, it is also necessary to establish measures to cope with loss of cardiopulmonary function that may occur spontaneously during endoscopy under sedation. In addition to the oxygen-supply equipment, emergency resuscitation tools, such as laryngeal mask, intubation instruments, and heart defibrillator, along with emergency medication, such as epinephrine, flumazenil, and naloxone, must be available for use.

3. Each bed in the examination room must be equipped with a patient monitoring system to monitor blood pressure, heart rate, and oxygen saturation.

Rationale: A patient monitoring system must be available to monitor blood pressure, heart rate, and oxygen saturation, because hypotension, hypertension, arrhythmia, or myocardial infarction may occur during an endoscopic procedure. A patient monitoring system includes a blood pressure manometer, a pulse measuring device, a pulse oximeter, and an electrocardiogram (ECG) monitor. ${ }^{5}$ The aim is to enable early detection of abnormal signs during an endoscopic examination. The pulse oximeter should be non-invasive, portable, and allow for continuous monitoring.

\section{Each bed in the examination room must be equipped with oxygen-supply equipment.}

Rationale: With the increasing number of elderly patients and patients with cardiopulmonary diseases, there is an increased likelihood of oxygen desaturation during endoscopy. In response to this, it is necessary that each bed is equipped with oxygen-supply equipment to supply oxygen, when necessary. In particular, as the use of endoscopy under sedation and lengthy therapeutic endoscopy is increasing and as sup- 
plying oxygen to patients during endoscopy under sedation is recommended, it is mandatory that the oxygen-supply equipment should be available.

\section{An ECG monitoring device must be available.}

Rationale: It is absolutely necessary to have equipment capable of measuring or monitoring ECG during endoscopy as hypotension, hypertension, arrhythmia, or myocardial infarction may occur during the procedure. In particular, the rapid increase in the number of patients requiring therapeutic endoscopy procedures has led to lengthier endoscopy under sedation and thus, there has been an increase in the number of cases that require intensive monitoring. Patient monitoring equipment, including an ECG monitor in the endoscopy unit, will help to detect any abnormalities by measuring or monitoring ECG when cardiac anomalies are suspected during an endoscopic examination or when patient history indicates a need for intensive heart monitoring.

\section{A portable oxygen tank that could be used any time must be available.}

Rationale: A portable oxygen tank must be available to provide aid if hypoxia develops after an endoscopic procedure, while it is also needed during transfer to the intensive care unit or to another hospital for additional care after emergency resuscitation. However, there are no data regarding the accurate number of portable oxygen tanks that are required per endoscopic examination room, indicating the need for further discussions.

\section{Recommended items 7 items}

\section{Facilities and areas: 7 items}

1. Endoscopy units that perform therapeutic endoscopic procedures are recommended to include a carbon dioxide insufflation system.

Rationale: Using a carbon dioxide insufflation system during colonoscopy can reduce post-procedure pain and cramps and increase the level of satisfaction for the procedure for both the patient and the physician, and thus, the availability of such of system is recommended. ${ }^{6,7}$

\section{Installation of an appropriate ventilation system is recommended for all endoscopic examination rooms.}

Rationale: The saliva, blood, and feces of the patients are collected in an endoscopic examination room, hence there is a high likelihood of exposure to various drugs. Moreover, since patients with various infectious diseases, including tuberculosis, may be examined in the endoscopy unit, it is absolutely necessary to be prepared for such situations. ${ }^{8,9}$ Therefore, a suitable ventilation system is recommended to minimize transmission of infection between patients and guarantee the safety of examination room employees.

\section{The door in each endoscopic examination room} should be of sufficient width to allow free passing of beds, while the size of the room should accommodate the bed, preparation cart, and emergency cart.

Rationale: An endoscopy unit must be equipped with an endoscopy system, bed, and accessories to enable proper endoscopic procedures. Thus, a suitably sized examination room should be available. Currently, there are not enough data regarding the appropriate size of endoscopic examination rooms, but the American Society for Gastrointestinal Endoscopy suggests $180 \mathrm{ft}^{2}\left(16.72 \mathrm{~m}^{2}\right)$ as an appropriate size for endoscopic examination rooms and 36 inches $(0.91 \mathrm{~m})$ as an appropriate door width. ${ }^{10} \mathrm{~A}$ previous survey found that the average size of endoscopic examination rooms in hospitals in Korea was $14.1 \mathrm{~m}^{2}$.

4. Endoscopy units are recommended to have a dedicated independent preparation room for the preparation, formulation, and storage of injections.

Rationale: Submucosal injection solutions, sedatives, other drugs, and infusions may be used during the endoscopic procedures, and thus, should be stored accordingly. In particular, safe preparation of injection materials for parenteral administration or endoscopic injection is very important. Thus, it is necessary to have an independent preparation room inside the endoscopy unit for preparation and formulation of injections in aseptic conditions.

There are some prerequisites for safe drug administration. An independent preparation room is required, which must not be in direct contact with patients or with the examination room. All drugs must be labeled, and disposable medical supplies must be clearly marked. Disposable infusion sets must be used in patients using aseptic techniques. Moreover, a disposable vial is preferred over a multi-dose vial, and syringes should not be reused. Used syringe and needles should be capped properly and disposed appropriately. Tube lubricants used during endoscopy may be used multiple times, and proper infection control measures should be applied. If the tube is suspected to be infected, it should be discarded immediately. ${ }^{9}$ Due to the lack of expert consensus on such space requirements or regulations in Korea, these are presented as recommended items. 
5. Endoscopy units are recommended to have a general recovery area to allow for patients recovery and stabilization before discharge.

Rationale: Patients should recover from pain or stress after an endoscopic procedure. Some patients may present with unstable vital signs or pain to sudden dizziness or fainting after a procedure. Therefore, it is necessary to provide patients with an area where they can recover until their blood pressure or heart rate stabilizes. Patients, who undergo endoscopy under sedation, may present with a sudden onset of symptoms, such as fainting while standing, despite intensive monitoring, and thus, an area where patients can recover while seated is also required.

\section{An independent area inside the endoscopy units} is required to provide education to employees and patients.

Rationale: With the increased importance of quality assurance in endoscopy, the importance of appropriate education for employees and patients has increased as well. ${ }^{4}$ Therefore, an adequately sized area for education is a mandatory requirement. However, as securing a necessary facility and space may require time and budget, this item is designated as a recommended item.

\section{Endoscopy units are recommended to include a} waiting/resting area for the medical staff.

Rationale: Endoscopy units represent an area where physicians, nurses, nursing assistants, and other medical assistants work. Published data have indicated that increased fatigue in medical personnel from continuously performing endoscopic procedures can lead to a decline in the quality of endoscopy. In addition, musculoskeletal fatigue due to performing the endoscopic procedure, changing patient's position, and moving around can also lead to a decline in the quality of care. In particular, therapeutic and emergency endoscopy present added pressure, and thus, an area for the medical staff to wait and rest is required. A changing room is also required to allow the medical staff to change their clothes. Due to lack of sufficient supporting evidence, this item is designated as a recommended item.

\section{RATIONALE BEHIND AQEU ASSESSMENT ITEMS FOR PROCESSES}

\section{Mandatory items 19 items}

Explanation and consent (entire examination processes): 8 items
1. Prior to endoscopic examination, the examiner or an assistant must verify the identity of the examinee by name and date of birth.

Rationale: A process for verifying the exact identity of examinee prior to endoscopic examination is required for accurate communication between the medical staff and to avoid confusion.

2. Information on the type of endoscopic examination, the reason for performing the procedure, and how the procedure will be performed must be provided prior to the procedure. ${ }^{11}$

Rationale: Prior to endoscopic examination, information must be provided to the examinee regarding the reason for performing the endoscopic procedure and the details about the endoscopic procedure.

3. The consent form for upper GI endoscopy must use a recommended format or contain all mandatory information. The complete consent should be obtained prior to the procedure.

Rationale: The consent form must contain information about the type of the scheduled endoscopic procedure, pre-procedure precautions, the process involved in the endoscopic procedure, potential problems and complications (hypersensitivity, hypoxia, respiratory complications, stroke, myocardial infarction, bleeding, perforation, and others) that may occur during the procedure, and post-procedure precautions. $^{12}$

4. The consent form for colonoscopy must use a recommended format or contain all mandatory information. The complete consent should be obtained prior to the procedure.

Rationale: The consent form must contain information about the type of scheduled endoscopic procedure, pre-procedure precautions, the process involved in the endoscopic procedure, potential problems and complications that may occur during the procedure (nausea/vomiting, abdominal discomfort/distention, hypothermia, fluid and electrolyte disturbance, nephrotoxicity, hypersensitivity, hypoxia, respiratory complications, stroke, myocardial infarction, bleeding, perforation, and others), and post-procedure precautions.

5. The consent form provided prior to the endoscopic examination must be signed by the medical staff and the examinee (or their legal representative).

Rationale: The consent form must include the signature of the medical personnel and the examinee or the consent 
holder. If the form is signed by a consent holder, the reason for signing on behalf of the examinee and the date must be included. In principle, the consent form should be personally signed by the examinee. However, a guardian or legal representative may act as a consent holder on behalf of the patient under the following circumstances: the patient has physical or mental impairment that makes it difficult to make decisions on their own, the patient is a minor, explanation of the content of the consent form may significantly impact the mental well-being of the examinee, and the patient has provided a power of attorney to someone else. In such cases, the reason for designating a consent holder must be recorded in the consent form.

6. For endoscopy under sedation, a recommended format must be used or all information needed for sedation consent must be included.

Rationale: The endoscopy under sedation consent form must include information about the sedative endoscopic procedure, the purpose and necessity of sedation, processes and methods of endoscopy under sedation, problems, complications, and sequelae associated with endoscopy under sedation, alternative treatment options other than endoscopy under sedation, and prognosis if left untreated.

7. Prior to an endoscopic examination, a pre-screening chart or evaluation report must be checked for fasting status; general conditions; disease history; medication history, including use of antithrombotic agents; teeth conditions (only for upper GI endoscopy only); and bowel preparation status (for colonoscopy only).

Rationale: To maximize the efficacy of an endoscopic procedure and minimize complications, risk assessment based on detailed medical history and physical examination is needed, along with appropriate responses to identify risks. Prior to an endoscopic procedure, it is necessary to check the medical history that may affect the procedure; general conditions that may increase the risk of endoscopy-related complications; and medical history that may affect treatments prior to endoscopy, including history of neck surgery (including the pharyngolarynx), liver cirrhosis, heart failure, bleeding tendency disease, renal insufficiency, artificial valve/pacemaker, history of endocarditis, asthma, chronic obstructive pulmonary disease, hypertension, diabetes, cerebrovascular disease, glaucoma, prostate hypertrophy, and allergy. For examinees administered antiplatelet agents or anticoagulants, the risk of bleeding versus thrombosis and embolism should be considered to determine whether the medications should be discontinued; in addition, it should be checked whether insulin/oral hy- poglycemic agent should be discontinued temporarily and determined whether antidepressants/sedatives are being administered.

8. Prior to colonoscopy, information must be provided to the examinee about the importance of bowel preparation and diet and use of a bowel-cleansing agent for bowel preparation. An information brochure must be distributed.

Rationale: To increase the detection rate of adenoma or colorectal cancer, which is the primary goal of colonoscopic examinations, adequate bowel preparation is a key prerequisite that determines the efficacy and quality of the examination. The importance of proper dietary control and proper use of a bowel-cleansing agent must be explained to the patient prior to the procedure to ensure a high-quality colonoscopic examination without missing important lesions.

\section{Examination processes (processes during examina-} tion): 8 items

\section{Images acquired during the endoscopic examina- tion must be saved as image files.}

Rationale: Images acquired during an endoscopic examination are also considered to be treatment data, and thus, saving and keeping such data for a specific period of time would be considered a mandatory item. Endoscopic images saved in printed form are considered not acceptable.

\section{Upper GI endoscopy images must include 8 imag-} es of standard imaging areas. When imaging the stomach, the entire stomach must be imaged and the images must be saved.

Rationale: The standard imaging areas for upper GI endoscopic examination are: (1) the upper esophagus, (2) the gastroesophageal junction, (3) the cardia, (4) the upper part of the gastric lesser curvature side, (5) the gastric angle, (6) the antrum, (7) the duodenal bulb, and (8) the second portion of the duodenum. At least 8 images must be acquired, including all areas listed above. ${ }^{13}$ Therefore, it is necessary to designate the standard imaging areas and the minimum number of images required.

3. The presence of Helicobacter pylori must be evaluated if a gastric or duodenal ulcer is found during upper GI endoscopic examination.

Rationale: Because H. pylori has already been identified as a major cause of gastric or duodenal ulcer, its presence must be checked. ${ }^{14}$ 
4. During colonoscopy, cecal intubation must be performed and whether cecal intubation was performed or not must be recorded in the report; images must be saved.

Rationale: Various colorectal diseases are prevalent in the right colon and the cecal intubation rate is a very important factor when assessing the quality of colonoscopy. ${ }^{15-17}$ Therefore, it is absolutely necessary to ensure that colonoscopy included imaging of the cecal area.

5. Colonoscopy imaging must include images of the maximum intubation site and at least 8 images of standard imaging areas, in the observed order, when there are no local lesions; additional clear images must be acquired as proof that the examination was performed sufficiently with scoping of the entire colon.

Rationale: The standard imaging areas for colonoscopy include (1) the cecum, including the appendiceal opening; (2) the ileocecal valve; (3) the distal part of the ascending colon to the area directly superior to the hepatic flexure; (4) the proximal transverse colon directly inferior to the hepatic flexure (including the liver shadow); (5) the distal transverse colon directly superior to the splenic flexure; (6) the descending colon to the area direction inferior to the splenic flexure; (7) the middle segment of the sigmoid colon; and (8) the entire rectum up to $2 \mathrm{~cm}$ superior to the anal verge. At least $8 \mathrm{imag}$ es must be acquired, including the maximum intubation site and all areas listed above. Basic images of different parts of the entire colon must be acquired during the colonoscopy, which would serve as evidence that the examination was performed adequately.

6. During colonoscopy, the examination time must be checked and the average withdrawal time, indicating the pure observation time during colonoscopy, must be at least 6 minutes.

Rationale: During a colonoscopy, the withdrawal time must be sufficient to assure that important lesions were not overlooked. The average colonoscopy withdrawal time for assuring adequate level of quality is at least 6 minutes and improvement in detection rate or preventive effect can be achieved by meeting this requirement. ${ }^{18}$

7. Tissue biopsy must be performed on any abnormal findings detected during an endoscopic examination.

Rationale: Abnormal findings in an endoscopic examination include ulcers, cancer-suspicious lesions, adenoma, and dysplasia. When abnormal findings are observed in an endo- scopic examination, tissue biopsy is absolutely necessary for a definitive diagnosis of the lesion. ${ }^{19}$ In particular, the tissue biopsy should be performed on the most advanced part after thoroughly observing the lesion. Since the risk of complications, such as bleeding, is present, smooth manipulation of the endoscope should be encouraged.

\section{Appropriate response measures for AEs that may occur during an endoscopic examination must be known and implemented accordingly. \\ Rationale: Endoscopic examination is a relatively safe pro- cedure, but AEs may occur in rare cases. Awareness of the possibility of all AEs should be communicated as much as possible in an effort to prevent and respond to such AEs. ${ }^{20}$ When AEs occur, appropriate response measures must be tak- en and records of such measures must be maintained.}

\section{Examination processes (processes after examina-} tion): 3 items

1. The patient must be notified after the endoscopic examination about the necessity of the tissue biopsy or $H$. pylori test performed during the procedure and how to obtain access to the results.

Rationale: Sufficient information must be provided to the examinees to ensure that they understand why a $H$. pylori test was necessary during the endoscopic examination or why a tissue biopsy was performed for definitive diagnosis when an abnormal lesion was found. In addition, information must be provided regarding the exact amount of time required for pathological diagnosis and procedures for obtaining the test results when they become available.

\section{Verbal or written information about precautions} or possible complications must be provided to the examinee prior to discharge.

Rationale: It is necessary to inform the examinee about delayed symptoms that may appear after an endoscopic procedure and how to respond to such complications to prevent serious complications before they actually occur. ${ }^{21}$ For examinees who underwent an endoscopic procedure under sedation, the explanation should include recommendations not to operate a motor vehicle or make major decisions.

\section{Records must be kept regarding the management} of specimens acquired during endoscopic examinations.

Rationale: Records about patients who underwent tissue biopsy are necessary for proper management of specimens. ${ }^{22}$ 


\section{Recommended items 1 item}

1. Guidelines regarding revisions and changes to the endoscopic examination reports are required.

Rationale: Any changes to a submitted endoscopic examination report should be made in accordance with the designated regulations and guidelines.

\section{AQEU ASSESSMENT ITEMS FOR PERFORMANCE INDICATORS AND RATIONALE BEHIND AQEU ASSESSMENT ITEMS FOR PERFORMANCE INDICATORS}

\section{Mandatory items 10 items}

\section{Indicators by procedure - upper GI endoscopy: 1 item}

\section{The endoscopy report must include information} that could be used to verify the following items:

(1) Examination date, (2) name, (3) sex, (4) age, (5) registration number, (6) person who performed the endoscopic procedure, (7) details about drugs used (spasmolytic, sedative, etc.), (8) biopsy status, (9) observational findings, (10) diagnosis, and (11) Helicobacter pylori test status.

Rationale: An endoscopy report also serves as objective evidence for the quality of the procedure, including pre-treatment of the examination, diagnosis, and post-procedure safety assessment. Therefore, the items described above must be thoroughly checked and described in the report.

\section{Indicators by procedure - colonoscopy: 3 items}

\section{The endoscopy report must include information that could be used to verify the following items:}

(1) Examination date, (2) name, (3) sex, (4) age, (5) registration number, (6) person who performed the endoscopic procedure, (7) details about drugs used (spasmolytic, sedative, etc.), (8) biopsy status, (9) observational findings, (10) diagnosis, (11) cecal intubation status, (12) bowel preparation status, and (13) endoscopic procedure time and withdrawal time.
Rationale: Just as with upper GI endoscopy, the colonoscopy report serves as objective evidence, and thus, it must be drafted faithfully. For cecal intubation, the report must include images of the ileocecal valve or the whole cecum, including the appendiceal opening, and descriptions of the images. Moreover, the degree of bowel preparation must be scored and written in the report. Herein, withdrawal time is defined as the pure observation time, excluding time spent for polypectomy or tissue biopsy.

2. The report must provide the results from a digital rectal examination and observation of the outside of the anus prior to performing the endoscopic procedure.

Rationale: Evaluation of the perianal area by visual inspection, palpation, and anal tone prior to inserting the endoscope can be very useful in assessing various anal diseases, including hemorrhoids, anal fissure, anal mass, and motor disorders such as fecal incontinence. ${ }^{23}$

3. The adequate bowel preparation rate among all monthly colonoscopic examinations must be maintained at $\geq \mathbf{8 0} \%$.

Rationale: Despite the fact that adequate bowel preparation is required for a thorough examination of lesions during colonoscopy, some researchers have reported up to $30 \%$ of cases with poor bowel preparation. ${ }^{24-26}$ Various national and foreign guidelines recommend that the minimum rate of adequate bowel preparation should be maintained at $\geq 80 \%$ for cases involving colon without any surgical or anatomical abnormal findings. ${ }^{16,17,27}$

\section{Indicators by procedure - common: 4 items}

1. When lesions (ulcer or polyp) were found during the examination, the endoscopy report must describe (1) number, (2) location, (3) gross morphology, and (4) size of the lesion(s).

Rationale: The endoscopist must objectively record information about all lesions found during the endoscopic procedure in the endoscopy report; objective information must include the number, location, gross morphology, and size of the lesions.

2. When an endoscopic treatment was performed on lesion(s), the endoscopy report must contain information verifying (1) treatment method and (2) request for histologic evaluation when the lesion was removed.

Rationale: If a therapeutic endoscopic procedure was per- 
formed on lesion(s) found during endoscopy, the endoscopist must describe the details of the procedural method used in the endoscopy report to allow such information to be used as objective evidence for follow-up examinations or re-treatment of the lesion(s).

3. The indication(s) for the endoscopic examination must be clearly stated in the endoscopy report.

Rationale: The endoscopist must verify the indications for performing the endoscopic procedure and approach the procedure considering the predicted lesions based on these indications. The records of the indications for the endoscopic procedure could be used as objective evidence for diagnosis and treatment by endoscopy and may be informative for determining the follow-up examination period.

\section{After endoscopy, complications associated with} the examination must be described in the endoscopy report.

Rationale: The endoscopist must objectively record, in the endoscopy report, the complications that occurred during an endoscopic procedure, to inform future treatments and to help to improve patient safety outcomes.

\section{Longitudinal data: 2 items}

\section{Monthly statistics on the number of endoscopic} procedures performed must be available.

Rationale: In addition to facility, equipment, and competency of the endoscopist, all endoscopic procedures are directly affected by the time of day that the procedure is performed, procedure length, interval between procedures, and fatigue of the endoscopist. ${ }^{1721}$ Each institution must provide monthly statistics on diagnostic and therapeutic endoscopic procedures performed. The statistics must be used to check and record whether an appropriate number of procedures are being performed based on the number of endoscopists.

\section{Monthly statistics on the number of patients who} underwent blood transfusion, were hospitalized, or underwent surgery for complications that occurred during the endoscopic procedure must be available.

Rationale: The incidence of complications must be calculated and prevention of recurrence of such complications must be addressed.

\section{Recommended items 4 items}

Indicators by procedure - common: 1 item

1. The endoscopy report is recommended to include any major disease history (hypertension, diabetes, heart disease, liver disease, etc.) and medication history (antithrombotic agents and medication for hypertension, diabetes, or other).

Rationale: The endoscopist must objectively record, in the endoscopy report, information pertaining to disease and medication history of the examinee and this information could be used as objective evidence to determine treatment and prevention of complications associated with endoscopic procedures.

\section{Longitudinal data: 3 items}

\section{Calculation of monthly statistics on adenoma detection rate following colonoscopy is recom- mended.}

Rationale: Adenoma detection rate (ADR) is significantly negatively correlated with incidence of interval colorectal cancer and is known to be an important indicator, among various quality indicators, for colonoscopy ${ }^{17,28}$ The American Society for Gastrointestinal Endoscopy/American College of Gastroenterology Taskforce on Quality in Endoscopy determined that $\mathrm{ADR}$ is $\geq 25 \%$ and $15 \%$ in asymptomatic male and female patients, respectively. ${ }^{15}$

\section{Calculation of monthly statistics on the detection} rate of cancer following upper GI endoscopy or colonoscopy is recommended.

Rationale: Early cancer detection is one of the most important reasons for performing upper GI endoscopy or colonoscopy. In particular, when gastric cancer is detected early, there is a higher probability of cure with a 5 -year survival rate over $95 \%$. Therefore, all endoscopic examination results for each month should be reviewed and monthly statistics on the detection of gastric and colorectal cancer should be calculated and recorded in an ongoing effort to identify the level of cancer detection and to improve cancer detection rate.

3. Statistics on complications associated with sedation.

Collection of statistical data on the assessment of the level of sedation during endoscopy under sedation and complications associated with sedation is recommended. 
Rationale: Records serve as objective evidence for the quality of a procedure, including pre-treatment prior to the examination and safety assessment during and after the procedure; thus, records must be thoroughly completed.

\section{CONCLUSIONS}

This document provides updates on quality indicators, such as facility/equipment, process and outcome measures, in Korea. Some quality indicators show low level of evidence and were based on expert opinion. However, this updated guideline will be useful to establish competence and help to define areas of continuous quality improvement in Korean endoscopic practice. Future studies should be performed to address the lack of evidence to support our AQEU assessment items.

\section{Conflicts of Interest}

The authors have no financial conflicts of interest.

\section{ORCID}

Jin Young Yoon: https://orcid.org/0000-0002-5280-0443

Chang Nyol Paik: https://orcid.org/0000-0002-3470-6904

Hyuk Soon Choi: https://orcid.org/0000-0002-4343-6950

Jae-Young Jang: https://orcid.org/0000-0002-7930-1468

\section{REFERENCES}

1. Mulder CJ, Tan AC, Huibregeste K. Guidelines for designing an endoscopy unit: report of the Dutch Society of Gastroenterologists. Endoscopy 1997;29:I-VI.

2. Rey JF. Quality control on endoscopic maintenance and repair services: safety considerations for the patient. Dig Dis 2008;26:7-10.

3. Francis DL. Automated processes to improve the quality and safety in an endoscopic practice. Clin Gastroenterol Hepatol 2014;12:540-543.

4. ASGE Endoscopy Unit Quality Indicator Taskforce, Day LW, Cohen J, et al. Quality indicators for gastrointestinal endoscopy units. VideoGIE 2017;2:119-140.

5. Rizk MK, Sawhney MS, Cohen J, et al. Quality indicators common to all GI endoscopic procedures. Gastrointest Endosc 2015;81:3-16.

6. Sajid MS, Caswell J, Bhatti MI, Sains P, Baig MK, Miles WF. Carbon dioxide insufflation vs conventional air insufflation for colonoscopy: a systematic review and meta-analysis of published randomized controlled trials. Colorectal Dis 2015;17:111-123.

7. ASGE Technology Committee, Lo SK, Fujii-Lau LL, et al. The use of carbon dioxide in gastrointestinal endoscopy. Gastrointest Endosc 2016;83:857-865.

8. Atkinson J, Chartier Y, Pessoa-Silva CL, Jensen P, Li Y, Seto WH, eds. Natural ventilation for infection control in health-care settings. Vol. 3, Infection and ventilation. Geneva: World Health Organization; 2009.

9. ASGE Quality Assurance in Endoscopy Committee, Calderwood AH,
Day LW, et al. ASGE guideline for infection control during GI endoscopy. Gastrointest Endosc 2018;87:1167-1179.

10. ASGE Ensuring Safety in the Gastrointestinal Endoscopy Unit Task Force, Calderwood AH, Chapman FJ, et al. Guidelines for safety in the gastrointestinal endoscopy unit. Gastrointest Endosc 2014;79:363-372.

11. Bjorkman DJ, Popp JW Jr. Measuring the quality of endoscopy. Gastrointest Endosc 2006;63(4 Suppl):S1-S2.

12. Cohen J, Safdi MA, Deal SE, et al. Quality indicators for esophagogastroduodenoscopy. Gastrointest Endosc 2006;63(4 Suppl):S10-S15.

13. Park WG, Shaheen NJ, Cohen J, et al. Quality indicators for EGD. Am J Gastroenterol 2015;110:60-71.

14. Min JK, Cha JM, Cho YK, et al. Revision of quality indicators for the endoscopy quality improvement program of the National Cancer Screening Program in Korea. Clin Endosc 2018;51:239-252.

15. Rex DK, Petrini JL, Baron TH, et al. Quality indicators for colonoscopy Am J Gastroenterol 2006;101:873-885.

16. Rex DK, Schoenfeld PS, Cohen J, et al. Quality indicators for colonoscopy. Gastrointest Endosc 2015;81:31-53.

17. Rees CJ, Thomas Gibson S, Rutter MD, et al. UK key performance indicators and quality assurance standards for colonoscopy. Gut 2016;65:1923-1929.

18. European Colorectal Cancer Screening Guidelines Working Group, von Karsa L, Patnick J, et al. European guidelines for quality assurance in colorectal cancer screening and diagnosis: overview and introduction to the full supplement publication. Endoscopy 2013;45:51-59.

19. Valori R, Cortas G, de Lange T, et al. Performance measures for endoscopy services: a European Society of Gastrointestinal Endoscopy (ESGE) quality improvement initiative. Endoscopy 2018;50:1186-1204.

20. Faigel DO, Pike IM, Baron TH, et al. Quality indicators for gastrointestinal endoscopic procedures: an introduction. Gastrointest Endosc 2006;63(4 Suppl):S3-S9.

21. Rutter MD, Senore C, Bisschops R, et al. The European Society of Gastrointestinal Endoscopy quality improvement initiative: developing performance measures. United European Gastroenterol J 2016;4:30-41.

22. Siau K, Green JT, Hawkes ND, et al. Impact of the Joint Advisory Group on Gastrointestinal Endoscopy (JAG) on endoscopy services in the UK and beyond. Frontline Gastroenterol 2019;10:93-106.

23. Tantiphlachiva K, Rao P, Attaluri A, Rao SS. Digital rectal examination is a useful tool for identifying patients with dyssynergia. Clin Gastroenterol Hepatol 2010;8:955-960.

24. Vanner SJ, MacDonald PH, Paterson WG, Prentice RS, Da Costa LR, Beck IT. A randomized prospective trial comparing oral sodium phosphate with standard polyethylene glycol-based lavage solution (Golytely) in the preparation of patients for colonoscopy. Am J Gastroenterol 1990;85:422-427.

25. Kolts BE, Lyles WE, Achem SR, Burton L, Geller AJ, MacMath T. A comparison of the effectiveness and patient tolerance of oral sodium phosphate, castor oil, and standard electrolyte lavage for colonoscopy or sigmoidoscopy preparation. Am J Gastroenterol 1993;88:1218-1223.

26. Kazarian ES, Carreira FS, Toribara NW, Denberg TD. Colonoscopy completion in a large safety net health care system. Clin Gastroenterol Hepatol 2008;6:438-442.

27. ASGE Standards of Practice Committee, Saltzman JR, Cash BD, et al. Bowel preparation before colonoscopy. Gastrointest Endosc 2015;81:781794.

28. Kaminski MF, Regula J, Kraszewska E, et al. Quality indicators for colonoscopy and the risk of interval cancer. N Engl J Med 2010;362:17951803. 